\title{
Acute Deterioration of an Intubated COPD Patient - A Case Report
}

\author{
Chris Sara Mathew ${ }^{1} \&$ Ediwn Dias ${ }^{2 \& 3}$
}

${ }^{1}$ Ph.D. Scholar, College of Allied Health Sciences, Srinivas University Mangalore, India. ${ }^{2}$ Adjunct Professor, College of Allied Health Sciences, Srinivas University, Mangalore, India.

${ }^{3}$ Professor and HOD, Department of Pediatrics, Srinivas Institute of Medical Sciences and Research Centre, Mangalore, India.

Email: edwindias@gmail.com

Type of the Paper: Case Report.

Type of Review: Peer Reviewed.

Indexed In: OpenAIRE.

DOI : https://doi.org/10.5281/zenodo.2585542.

Google Scholar Citation: IJHSP

How to Cite this Paper:

Mathew., Chris Sara \& Dias, Edwin. (2019). Acute deterioration of an inctbated COPD patient - A case report. International Journal of Health Sciences and Pharmacy (IJHSP), 3(1), 1- 5. DOI: https://doi.org/10.5281/zenodo.2585542.

International Journal of Health Sciences and Pharmacy (IJHSP)

A Refereed International Journal of Srinivas University, India.

(C) With Authors.

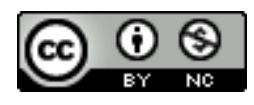

This work is licensed under a Creative Commons Attribution-Non Commercial 4.0 International License subject to proper citation to the publication source of the work.

Disclaimer: The scholarly papers as reviewed and published by the Srinivas Publications (S.P.), India are the views and opinions of their respective authors and are not the views or opinions of the SP. The SP disclaims of any harm or loss caused due to the published content to any party. 


\title{
Acute Deterioration of an Intubated COPD Patient - A Case Report
}

\author{
Chris Sara Mathew ${ }^{1}$ \& Ediwn Dias ${ }^{2 \& 3}$ \\ ${ }^{1}$ Ph.D. Scholar, College of Allied Health Sciences, Srinivas University Mangalore, India. \\ ${ }^{2}$ Adjunct Professor, College of Allied Health Sciences, Srinivas University, Mangalore, India. \\ ${ }^{3}$ Professor and HOD, Department of Pediatrics, Srinivas Institute of Medical Sciences and \\ Research Centre, Mangalore, India. \\ Email: edwindias@gmail.com
}

\begin{abstract}
Dealing with respiratory failure associated with exacerbation of chronic obstructive pulmonary disease (COPD) is not an uncommon scenario in intensive care units (ICUs). We present the case of an elderly man presenting to the emergency department (ED) with an infective exacerbation of COPD due to community acquired pneumonia. This case highlights an unexpected event following definitive airway management and its clinical course.
\end{abstract}

Keywords: Chronic obstructive pulmonary disease, Endotracheal tube.

\section{INTRODUCTION :}

Difficulty in ventilating an intubated patient, as a result of endotracheal tube (ETT) related issues, is known in acute care practice. Mechanical ventilator malfunction, obstruction of breathing circuit, poor lung compliance and increases airway resistance are some of the common causes which make ventilation difficult in an intubated patient. Obstruction of an ETT is a potentially lifethreatening event. Obstruction by secretions, blood or tube kinking are some of the ETT related issues and obstruction from a structural defect of ETT is also seen. When difficulty in ventilation through an ETT is encountered, a quick differential diagnosis is warranted, which includes bronchospasm, pneumothorax, chest wall rigidity and equipment malfunction. We report a case of a COPD patient, who was intubated for respiratory issues and the following events related to intubation.

\section{THE CASE :}

A 61 year old cachectic man, known case of COPD, was brought to the ED with complaints of fever, productive cough and persistent right sided chest pain. Detailed evaluation revealed that, the patient had pleuritic type chest pain since last month, yellowish sputum with no hemoptysis, weight loss of approximately $13 \mathrm{~kg}$ over the last 6 months and had night sweats. There was no history of fever, chills, myalgia or vomiting or any contact with sick patients or recent travel history. Subjective history, revealed exposure tuberculosis. The patient smoked one pack of cigarette daily for the past 40 years and did not agree to any recreational drug use. The patient's past medical history was suggestive of chronic tremors of the upper extremities for which he has not sought medical attention. $\mathrm{He}$ is on regular treatment for COPD. He had a previous admission to the ICU elsewhere for the treatment of community-acquired pneumonia and acute exacerbation of COPD.

On arrival at our medical ICU, the patient appeared to be dyspneic, and was unable to articulate or complete his sentences. His blood pressure was 148/71 mm Hg, heart rate of $138 / \mathrm{min}$, temperature $100{ }^{\circ} \mathrm{F}$, respiratory rate $37 / \mathrm{min}$, and oxygen saturation $78 \%$ on room air. Cardiac evaluation revealed tachycardia with regular rhythm, a normal S1 and S2 with 
no murmurs, gallops or rubs. On auscultation of the lung fields, breath sounds were diminished on the right upper chest with few crackles heard. The abdomen was soft with noorganomegaly. Extremities showed digital clubbing with no edema. He was oriented only to persons, but had an inability to pay attention or remember immediate events. He was moving all four extremities with slightly brisk deep tendon reflexes. Neck was supple and the pupils were brisk and reacting to light.

He was initiated on antibiotics (macrolides and $3^{\text {rd }}$ generation cephalosporin), inhaled bronchodilators, steroids and noninvasive ventilation (NIV). With NIV and a fraction of inspired oxygen (FiO2) of $55 \%$ his oxygen saturation (SpO2) came up to $92 \%$. On the subsequent day, his respiratory status started worsening demanding an increase in $\mathrm{FiO} 2$. He was more in distress with a respiratory rate of $40+$ and a $\mathrm{SpO} 2$ of $<80$ on $80 \% \mathrm{FiO} 2$, with a relatively acceptable hemodynamics. The patient started to have neurological deterioration with confusion, memory loss, drowsiness, visual hallucinations and worsening upper extremity tremors.

His subjective and objective deterioration demanded the need for endotracheal intubation in view with anticipatory cardio respiratory compromise. The patient was intubated with size $8.5 \mathrm{~mm}$ ID endotracheal tube (ET tube), and was connected to mechanical ventilation. Tracheal intubation was confirmed with end tidal capnography and 5 point auscultation. A Chest X-ray was also done, to confirm the position of ET tube. Intubation and post-intubation phase was uneventful. After 20 minutes, there was a sudden deterioration in oxygenation and hemodynamic parameters, with bradycardia and hypotension. High pressure alarms kept on beeping on the ventilator. The patient was disconnected from ventilator and connected to a selfinflating bag to ventilate. Bag ventilation was found to be resistant and diminished air entry was heard all over on auscultation. To rule out the other possible causes of deterioration, we looked for dislodgement of tube and found it to be insitu. Pneumothorax was suspected, and was ruled out by lung ultrasound. The mnemonic DOPE (Dislodgement of tube, Obstruction of tube, Pneumothorax and Equipment failure) was recollected here and it pointed more towards ET tube obstruction, in view with resistance in hand ventilation.

An open endotracheal suction was tried, but the catheter did not pass beyond $10 \mathrm{~cm}$ length. This lead to the conclusion of a tube block. An immediate chest x-ray was done and is revealed to be a bilateral lung collapse. The patient was extubated by inserting a continuous suction catheter in to the tube and was immediately reintubated with a $9.0 \mathrm{~mm}$ ID ET tube. The extubated tube had a massive thick mucus plug which was yellow in color. It was sent to the lab for further investigation.

Soon after the reintubation and reinstitution of mechanical ventilation the patient's oxygen saturation and hemodynamics improved. A chest x-ray was repeated and showed a reopened lung with good aeration. The patient was ventilated for the next two days and weaned off and extubated on the third day based on the subjective and objective criteria.

\section{DISCUSSION :}

Exacerbations of COPD is multi-factorial, which include environmental irritants, heart failure, noncompliance with prescribed medication and bacterial or viral infections being the most common. In our patient, due to his acute infectious phase and inability of secretion clearance resulted in further worsening of respiratory failure and intubation. The presence of ET tube directly inhibits with the mucociliary function and weakens the cough reflex, the two primary airway clearance mechanisms 
[1-4]. The underlying disease process that causes the inability to clear secretions may lead to the accumulation of mucus and result in secretion adherence at the airways and eventually, within the ET tube lumen [4-7].

In a mechanically ventilated patient, obstruction of the ET tube or artificial airway should always be suspected on observing abnormally higher peak inspiratory pressures, a decreased lung compliance, an increased resistance to inflation, and a considerable difference between inhaled and exhaled tidal volumes. ET tube obstruction in the intubated patient may be identified by passing an appropriate size suction catheter to assure patency of the tube. Other things to consider are equal breath sounds upon auscultation, review of the chest radiograph to assess appropriate ET tube position, asymmetry in chest rise during ventilation, and an acute change in vital signs and oxygen saturation.

There are many steps to be considered when assessing an intubated patient with acute deterioration in ventilation or oxygenation. It is a common practice that the patient is extubated and reintubated, when cardiopulmonary status is deteriorating, due to possible ET tube related complications [8]. The mnemonic 'DOPE', is often used to identify the cause of acute worsening of ventilated patients, where ' $D$ ' stands for dislodgement of the ET tube, 'O' for obstruction of tube, ' $\mathrm{P}$ ' for pneumothorax and ' $E$ ' for equipment failure $[8,9]$.

The case scenario discussed here was an acute exacerbation of COPD secondary to infection which is one of the common scenario requiring intensive care unit admission. The patient was expected to improve with non-invasive ventilation and other reliever medications, but eventually ended up in intubation. Since this patient is a known case of infective exacerbation of COPD requiring ventilator support, endotracheal intubation and bag ventilation might have resulted in dislodgement of underlying mucus from the lower airway, eventually clogging the ET tube. During this period, it is important to observe for changes in ventilator peak pressure alarms and subjective resistance to manual bag resuscitation. A steady increase or an abrupt rise in the ventilation pressures suggests the risk of dislodgement of thick mucus plug and impending catastrophe.

In our case, post intubation phase was worsened as the mucus plug occluded the ET tube, making a 'difficult to ventilate' scenario. Timely interpretation using the DOPE mnemonic helped the clinicians to identify and troubleshoot the unpleasant event.

\section{REFERENCES:}

[1] Trawöger, R, Kolobow, T, Cereda, M, Sparacino, ME Tracheal mucus velocity remains normal in healthy sheep intubated with a new endotracheal tube with a novel laryngeal seal. Anesthesiology. 1997; 86: 1140-1144.

[2] Sackner, MA, Hirsch, J, Epstein, S Effect of cuffed endotracheal tubes on tracheal mucous velocity. Chest. 1975; 68: 774-777.

[3] Knowles, MR, Boucher, RC Mucus clearance as a primary innate defense mechanism for mammalian airways. J Clin Invest. 2002; 109: 571-577.

[4] Glass, C, Grap, MJ, Sessler, CN Endotracheal tube narrowing after closed-system suctioning: Prevalence and risk factors. Am J Crit Care. 1999; 8: 93-100.

[5] Konrad, F, Schreiber, T, Brecht-Kraus, D, Georgieff, M Mucociliary transport in ICU patients. Chest. 1994; 105: 237-241.

[6] Van Surell, C, Louis, B, Lofaso, F, Beydon, L, Brochard, L, Harf, A, Fredberg, J, Isabey, D Acoustic method to estimate the longitudinal 
area profile of endotracheal tubes. Am J Respir Crit Care Med. 1994; 149: 28-33.

[7] Shah, C, Kollef, MH Endotracheal tube intraluminal volume loss among mechanically ventilated patients. Crit Care Med. 2004; 32: 120-125.

[8] Johnson KMJ, Lehman RE. Acute management of the obstructed endotracheal tube. Respir Care. 2012;57:1342-1344.

[9] Arney KL, Judson MA, Sahn SA. Airway obstruction arising from blood clot: three case-reports and a review of literature. Chest 1999; 115:293-300. 